\section{Kurz notiert}

Pflanzentrio lindert Harnwegsinfekte $>$ Bei leichteren Harnwegsinfekten und Reizblase kann das Phytotherapeutikum Canephron ${ }^{\circledR}$ eingesetzt werden. Das Präparat enthält Liebstöckelwurzel, Rosmarinblättern und Tausendgüldenkraut und besitzt diuretische, spasmolytische, antiphlogistische und antimikrobielle Effekte. Die Wirkung bei akutem Harnwegsinfekt ist darauf zurückzuführen, dass die Bakterien ausgespült werden, die Blasenmuskulatur sich entspannt, die Entzündung der Blasenschleimhaut zurückgeht und damit auch die Schmerzen beim Wasserlassen. Ein frühzeitiger Behandlungsbeginn kann daher den Einsatz von Antibiotika ersparen. Bei überaktiver Blase (Reizblase) machen sich die spasmolytischen und antiphlogistischen Wirkung des Phytotherapeutikums positiv bemerkbar.

Bionorica

HIV-Schnelltest sicher $>$ Auf den HIV-Schnelltest Determine ${ }^{\circledR}$ HIV-1/2 Ag/Ab Combo ist Verlass. Der Swiss HIV Cohort Study zufolge erreicht der Test eine Sensitivität von $100 \%$ : Keine der 300 chronisch HIV-Infizierten wurde falsch negativ getestet und auch bei den 69 HIV-negativen Kontrollpersonen gab es kein falsch positives Resultat. Dieses Ergebnis bestätigt frühere Studien und beendet die Diskussion um Studienergebnisse aus dem Vorjahr, die vermutlich aufgrund einer fehlerhaften Testauswertung zustande kamen.

Der Test ist seit 2009 auf dem Markt. Er detektiert sowohl HIVAntikörper als auch das HIV-1 p24Antigen und schließt damit falsch negative Ergebnisse in nur 20 Minuten aus. Der Test kann mit Voll- und Kapillarblut sowie mit Serum oder Plasma durchgeführt werden.

Alere

Trotz Metformin bleibt $\mathrm{HbA}_{1 c}$ über 7,5\%

\title{
Zugabe von oralen Antidiabetika wenig aussichtsreich
}

_ Um vaskulären Komplikationen bei Typ-2-Diabetikern vorzubeugen, ist eine gute Stoffwechseleinstellung wichtig Damit sollte man rechtzeitig beginnen „Unser Ziel muss es sein, den $\mathrm{HbA}_{1 c}$-Wert von Anfang an niedrig zu halten“, so Priv.Doz. Dr. Thomas Kunt, Berlin. Das kann schon früh den Einsatz von Insulin erforderlich machen.

\section{Was eine Reduktion} um einen \%-Punkt bringt

Erhöhte $\mathrm{HbA}_{1 c}$-Werte sollten nicht zu lange toleriert werden, wie Kunt betonte. Denn Diabetiker sind als kardiovaskuläre Hochrisiko-Patienten einzustufen. Und auch mikrovaskuläre Schäden an Nieren und Augen zählen zu den häufigen Spätfolgen der Krankheit.

Eine verbesserte glykämische Kontrolle kann die Risiken deutlich mindern. So belegt z. B. die United Kingdom Prospective Diabetes Study eine überzeugende Verringerung der Komplikationsraten: 1\%-Punkt weniger im $\mathrm{HbA}_{1 \mathrm{c}}$ führte zu $21 \%$ weniger diabetesbezogenen Endpunkten, $14 \%$ weniger Myokardinfarkten, $12 \%$ weniger Schlaganfällen und 32\% weniger mikrovaskulären Komplikationen. Der Vorteil ist in allen vier Bereichen signifikant.

\section{Die Empfehlungen der DDG-Praxis-Leitlinie}

Die von der Deutschen Diabetes-Gesellschaft erstellte Praxis-Leitlinie zur Behandlung von Typ-2-Diabetikern empfiehlt als ideales Therapieziel einen $\mathrm{HbA}_{1 c}$-Wert unter 6,5\%. Für den Fall, dass die Patienten dieses Ziel mit Schulung Metformin und einer Änderung ihres Ernährungs- und Bewegungsverhaltens nach drei bis sechs Monaten nicht erreicht haben, bietet die Leitlinie zwei Optionen an:

(1) Liegt der $\mathrm{HbA}_{1 \mathrm{c}}$-Wert unter $7,5 \%$, dann kann die Zugabe eines weiteren oralen Antidiabetikums oder Nicht-Insulins genügen.
(2) Bei einem $\mathrm{HbA}_{1 c}$-Wert über $7,5 \%$ verspricht ein zusätzliches orales Antidiabetikum oft keinen ausreichenden Effekt mehr, so Kunt. Als zweiter Schritt wird dann empfohlen, das orale Antidiabetikum mit Insulin zu kombinieren, entweder mit einem Basalinsulin oder mit einem prandialen Insulin (etwa mit Insulin lispro (Liprolog ${ }^{\circledR}$ ). Kunt erinnerte daran, dass Insulin - neben der kombinierten nicht pharmakologischen Intervention - den stärksten $\mathrm{HbA}_{1 c}$-senkenden Effekt besitzt.

\footnotetext{
- Helga Brettschneider Ouelle: Satellitensymposium, DDG-Kongress, Stuttgart, 12. Mai 2010 (Veranstalter: Berlin-Chemie)
}

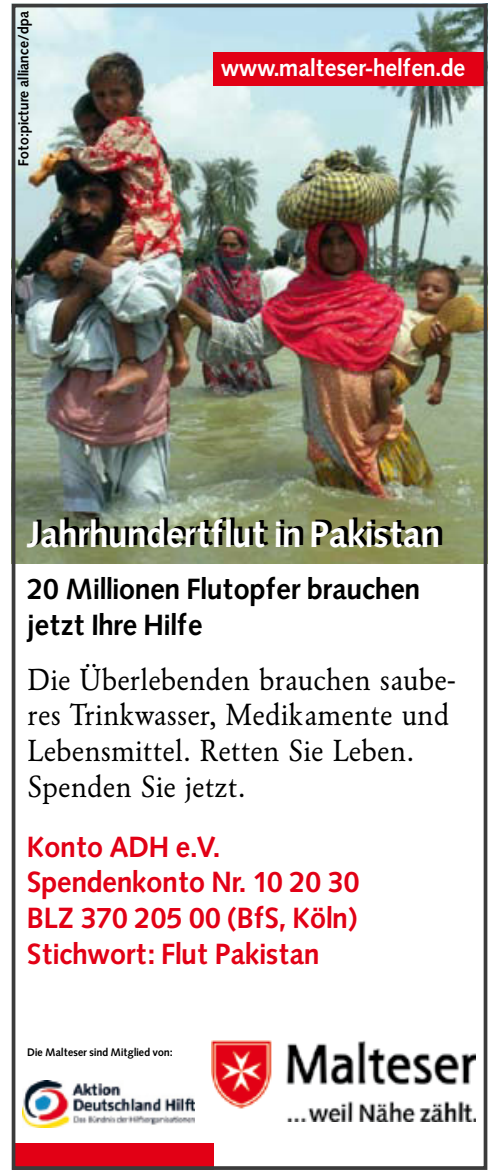

